\title{
Effect of Oscillatoria willei - a Marine Cyanobacterium on Hydrazine Induced Toxicity
}

\author{
Antony V.Samrot ${ }^{1 *}$ and T.Thirunalasundari ${ }^{2}$ \\ ${ }^{1}$ Department of Biotechnology, Sathyabama University, Chennai - 600119 , Tamil Nadu, India \\ ${ }^{2}$ Department of Biotechnology, Bharathidasan University, Tiruchirappalli - 620 024, Tamil Nadu, India \\ E.mail: drthirunalasundari@gmail.com
}

Received $20^{\text {th }}$ January 2012; Received in revised form $24^{\text {th }}$ April 2012; Accepted $30^{\text {th }}$ April 2012

\begin{abstract}
Aims: To find out the effect of crude extract of Oscillatoria willei, a marine cyanobacterium on hydrazine induced toxicity. Methodology and Results: In this study, the experimental mice were injected intramuscularly with $5 \mathrm{mg}$ of hydrazine/kg body weight continuously for 20 days. Crude extract of Oscillatoria willei was given to the animals induced with hydrazine toxicity. The animals were subjected to various biochemical and immunological parameters after exposing to hydrazine and followed up treatment. The results revealed that intra-peritoneal administration of $O$. willei reduced interleukin 2 (IL-2), reducing sugar, thiobarbituric acid reactive substances (TBARS), liver enzymes, bilirubin, creatinine and uric acid level.
\end{abstract}

Conclusion, significance and impact of study: $O$. willei treatment was found to reduce the ill effects induced by hydrazine.

Keywords: O. willei treatment was found to reduce the ill effects induced by hydrazine

\section{INTRODUCTION}

Hydrazine is a base, slightly weaker in strength than ammonia that can function as a strong reducing agent or as an oxidizing agent under certain conditions (Schiessl, 1995). At ambient temperature, hydrazine is a fuming, colorless, oily, hygroscopic liquid with an ammonia-like odor (National Research Council, 1996). Hydrazine has numerous industrial applications (Schiessl, 1995). It is used in the synthesis of many derivatives, including foaming or blowing agents, polymers, antioxidants, fungicides, herbicides, insecticides, plant growth regulators, and pharmaceuticals, such as the antibiotic isoniazid. Hydrazine is one of the components of tobacco smoke.

The quantity of hydrazine in mainstream cigarette smoke ranges from 24 to 43 nanograms (ng) per cigarette and an average of $32 \mathrm{ng}$ per cigarette (Liu et al., 1974; Hoffmann and Hecht, 1990). The quantity in side stream smoke (smoke emitted from a smoldering cigarette) might be higher than in mainstream smoke, for example $94 \mathrm{ng}$ (Liu et al., 1974). Symptoms due to high levels of hydrazine exposure include irritation of the eyes, nose and throat. It causes temporary blindness, dizziness, headache, nausea, pulmonary edema, seizures and coma in humans.

Adult male and female Fischer 344 rats and male Syrian hamsters exposed to hydrazine at $75 \mathrm{ppm}$ for $1 \mathrm{hr}$ each week for 10 weeks showed a significant reduction in body weight during the exposure period (Latendresse et al.,
1995). Hydrazine sulfate was found to induce hyperglycemia (Ochoa et al., 1975). Acute exposure can also damage the liver, kidneys and the central nervous system (CNS) in humans (International Agency for Research on Cancer, 1999). The carcinogenic effect of inhaled hydrazine in C57BL/6 mice, F344 rats, Syrian golden hamsters and beagle dogs has been reported (International Agency for Research on Cancer, 1999; Zhu et al., 1991).

On the basis of the animal bioassay data, hydrazine was classified by International Agency for Research on Cancer (1999) as possibly carcinogenic to humans (Group 2B) and by the U.S. Environmental Protection Agency (1991) as a probable human carcinogen (B2). Marine microalgae have emerged in the last 10 years as one of the most productive group for yielding substances of human health. Cyanobacteria are a diverse group of photosynthetic prokaryotic organisms. Morphologically they are of unicellular/colonial/filamentous forms.

The traditional use of cyanobacteria including as food has been established through centuries and through numerous and rigorous toxicological studies (Chamorro et al., 1997). In addition, Cyanobacteria are well known to produce various types of bioactive compounds that include antiviral, antibacterial, antifungal, immunomodulatory, antitumor and anticancer (Falch et al.,1995). Having known these facts, this study was done to explore the bioactive potency of Oscillatoria willei, a marine cyanobacterium on hydrazine induced pathological changes in mice model. 


\section{MATERIALS AND METHODS}

\section{Organism chosen}

The marine cyanobacterium Oscillatoria willei was chosen for this study. It is an autotrophic, filamentous organism. This strain was obtained from the germplasm collection of the National Facility for Marine Cyanobacteria (NFMC), Bharathidasan University, Tiruchirappalli - 620 024, India. The organism was cultured in ASN III N $\mathrm{N}^{+}$media in an auxenic condition and incubated at 1,500 lux. in the germplasm of the facility and were allowed to grow for 1520 days. After a duration of $15-20$ days, the mass was harvested using a sieve and was washed many times with tap water followed by distilled water to remove the salt. The fresh weight of the mass was obtained using an electronic balance (Precisa 125A, Switzerland). This wet mass was used for the preparation of extract. Cold ethanol extraction was done to get the extract.

\section{Experimental animal chosen for this study}

Apparently healthy Swiss albino male mice weighing around $30 \pm 0.7 \mathrm{~g}$ bodyweight were chosen for the study. The animals were obtained from the animal house of Department of Microbiology, Bharathidasan University, Tiruchirappalli - 620024 , India. The animals were housed in Tarson's polypropylene cages (8" $\times 12^{\prime \prime} \times 8$ ") with metal grill top and acclimatized to the laboratory conditions for a week in well ventilated room. The animals were fed with freshly prepared feed containing milk and wheat powder \& salt to taste and tap water ad libitum.

\section{Study Design}

The selected mice were divided into 5 groups containing 10 animals each. The $1^{\text {st }}$ control animals (G1) were not subjected to any treatment and next set of control animals (G2) received PBS pH 7.2 from $20^{\text {th }}$ day to $40^{\text {th }}$ day of the study period. Animals of the experimental group (G3) were injected with $5 \mathrm{mg}$ of hydrazine $/ \mathrm{kg}$ of animal for 20 days continuously, whereas the next test group (G4) were injected with $5 \mathrm{mg}$ of hydrazine $/ \mathrm{kg}$ of animal for 20 days continuously followed by treatment with Oscillatoria willei extract for the next 20 days $\left(20^{\text {th }}-40^{\text {th }}\right.$ day) and the test group G5 was left for recovery study after $O$. willei treatment.

\section{Analysis}

The animals were watched regularly for their general health condition, feed intake, water intake, excreta quantity and whole body weight. After the study period (20 days, 40 days $\& 60$ days) the animals were analyzed for hematological, immunological, biochemical and histological parameters. Before dissection the haematological parameters like bleeding time, clotting time, total count of erythrocytes (RBC) \& leukocytes (WBC), differential count and hemoglobin content (Sood,
2004) were seen. Gravimetric analysis of the various organs was done after dissection by weighing the organs in electronic balance (Sartorius). Serum was subjected for the estimation of Interleukin 2 (IL-2) (Hudson and Hay, 1989).

Serum biochemical analysis like reducing sugar (M/s Vital Diagnostics, Mumbai, India), total protein (M/s Beacon, Navsari, India), albumin (M/s Beacon, Navsari, India), total cholesterol and lipid profile (M/s Beacon, Navsari, India), triglyceride (M/s Vital diagnostics, Mumbai India), thio barbituric acid reactive substances (TBARS) (Yagi, 1992), liver function tests (AST, ALT, ALP, ACP and bilirubin) and kidney function tests (Urea, uric acid and creatinine) (M/s Agappe diagnostics, Kerala, India) were done by making use of respective commercial kits supplied by the corresponding companies given in the paranthesis. The histology of liver and lungs was studied adopting the routine paraffin method (Humason et al., 1971).

\section{Biochemical constituent of $O$.willei}

Tests for secondary metabolites were done by following the method adapted by Edeoga et al (2005).

\section{Gas Chromatography - Mass Spectroscopy (GC-MS)}

Chemical nature and molecular structure of the bioactive compounds present in the extract was analyzed using GC-MS (Clarus 500 Perkin Elmer model) at Paddy Processing Research Center, Thanjavur, Tamil Nadu, India.

\section{Statistical analysis}

All the results are presented as the mean \pm S.E.M. Statistical significance was noted by comparing each treatment group and the control by ANOVA followed by Duncan's post hoc test using SPSS software. Results with $p<0.001$ were considered statistically significant. Same legend on the table or figures indicates no significant difference.

\section{RESULTS AND DISCUSSION}

In this study, it was interesting to note that one animal of the hydrazine treated category developed skin tumor. The probable reason could be its mutagenic nature. Hydrazine is an irritant of skin and respiratory tract and also a carcinogen (International Agency for Research on Cancer, 1999). $50 \%$ of animals died after getting intramuscular injection with $10 \mathrm{mg}$ of hydrazine / $\mathrm{kg}$ of animal. There was a significant reduction of bodyweight and feed intake in hydrazine injected animals (Table 1). Weight loss was observed when hydrazine was absorbed through skin or inhaled or taken orally in human (Proctor and Hughes, 1978). O. willei had effect on body weight i.e. it brought back the weight loss due to hydrazine to certain extent. The reason could be the bioactive nature of secondary metabolites present in O. willei (Sarulatha, 2001). 
Table 1: Morphometric analysis

\begin{tabular}{|c|c|c|c|c|c|c|c|c|}
\hline \multirow[t]{3}{*}{ s.no } & \multirow[t]{3}{*}{ Category } & \multicolumn{7}{|c|}{ Parameters analysed } \\
\hline & & \multicolumn{2}{|c|}{ Body weight (g) } & \multirow[b]{2}{*}{ Feed intake $(\mathrm{g})$} & \multirow{2}{*}{$\begin{array}{c}\text { Excreta } \\
\text { quantity (g) } \\
\text { Liver }\end{array}$} & \multicolumn{3}{|c|}{ Gravimetry (g) } \\
\hline & & $\begin{array}{c}\text { Before } \\
\text { treatment }\end{array}$ & $\begin{array}{c}\text { After } \\
\text { treatment }\end{array}$ & & & Lungs & Spleen & Kidney \\
\hline 1. & G1 & $30.7 \pm 0.5$ & $31.6 \pm 0.33$ & $10.39 \pm 0.245$ & 1.16 & 0.145 & 0.059 & 0.322 \\
\hline 2. & G2 & $31.12 \pm 0.4$ & $31.5 \pm 0.5$ & $10.5 \pm 0.245$ & 1.16 & 0.145 & 0.058 & 0.353 \\
\hline 3. & G3 & $31.02 \pm 0.24$ & $27.42 \pm 0.4$ & $8.1 \pm 0.33$ & 1.455 & 0.262 & 0.176 & 0.404 \\
\hline 4. & G4 & $30.97 \pm 0.33$ & $28.02 \pm 0.33$ & $8.76 \pm 0.45$ & 1.25 & 0.225 & 0.137 & 0.434 \\
\hline 5. & G5 & $31.01 \pm 0.4$ & $28.52 \pm 0.6$ & $9.33 \pm 0.2$ & 1.20 & 0.215 & 0.09 & 0.351 \\
\hline
\end{tabular}

Table 2: Hemotological parameters seen in various group of animals

\begin{tabular}{|c|c|c|c|c|c|c|}
\hline \multirow[t]{2}{*}{ S.NO } & \multirow[t]{2}{*}{ Parameters analysed } & \multicolumn{5}{|c|}{ Category } \\
\hline & & $\mathrm{G} 1$ & G2 & G3 & G4 & G5 \\
\hline 1. & Bleeding time (s) & $51.7 \pm 1.78^{\mathrm{a}}$ & $51.2 \pm 1.32^{\mathrm{a}}$ & $42 \pm 1.14^{\mathrm{b}}$ & $46 \pm 1.14^{\mathrm{C}}$ & $47 \pm 1.2^{\mathrm{C}}$ \\
\hline 2. & Clotting time (s) & $123.5 \pm 3.06^{\mathrm{a}}$ & $122.25 \pm 2.08^{a}$ & $83.5 \pm 1.46^{\mathrm{b}}$ & $88.5 \pm 0.94^{c}$ & $96.7 \pm 1.78^{d}$ \\
\hline 3. & $\begin{array}{l}\text { WBC } \\
\mathrm{N} \times 10^{5} \text { cells } / \mathrm{mL}\end{array}$ & $33.75 \pm 1.13^{\mathrm{a}}$ & $33.65 \pm 1.46^{\mathrm{a}}$ & $46.5 \pm 1.78^{b}$ & $43.5 \pm 1.32^{b}$ & $40.42 \pm 1.46^{c}$ \\
\hline 4. & $\begin{array}{l}\mathrm{RBC} \\
\mathrm{N} \times 10^{8} \text { corpuscles } / \mathrm{mL}\end{array}$ & $41.4 \pm 1.13^{a}$ & $41.5 \pm 1.48^{a}$ & $33 \pm 1.78^{b}$ & $35 \pm 0.94^{b}$ & $36 \pm 1.13^{b}$ \\
\hline 5. & Hemoglobin $(\mathrm{gms} \%)$ & $12.47 \pm 0.94^{\mathrm{a}}$ & $12.35 \pm 1.13^{\mathrm{a}}$ & $9.2 \pm 0.04^{\mathrm{a}}$ & $11 \pm 0.48^{\mathrm{b}}$ & $11.2 \pm 0.33^{c}$ \\
\hline \multicolumn{7}{|c|}{ Differential count } \\
\hline 6. & Lymphocytes (\%) & $65 \pm 1.0^{\mathrm{a}}$ & $65 \pm 1.0^{\mathrm{a}}$ & $52 \pm 0.8^{b}$ & $54 \pm 1.01^{c}$ & $56 \pm 1.2^{\mathrm{d}}$ \\
\hline 7. & Lymphocytes (\%) & $25 \pm 1.12^{\mathrm{a}}$ & $25 \pm 0.8^{a}$ & $20 \pm 0.54^{b}$ & $21 \pm 0.5^{\mathrm{b}}$ & $25 \pm 0.37^{a}$ \\
\hline 8. & Neutrophil (\%) & $9 \pm 0.68^{\mathrm{a}}$ & $9 \pm 0.51^{a}$ & $22 \pm 1.07^{\mathrm{b}}$ & $21 \pm 0.93^{b}$ & $17 \pm 1.24^{c}$ \\
\hline 9. & Monocyte (\%) & $0^{a}$ & $0^{a}$ & $4 \pm 0.24^{\mathrm{b}}$ & $3 \pm 0.1^{\mathrm{b}}$ & $1 \pm 0.001^{c}$ \\
\hline 10. & Basophil(\%) & $1 \pm 0.02^{a}$ & $1 \pm 0.02^{\mathrm{a}}$ & $2 \pm 0.24^{b}$ & $1 \pm 0.2^{\mathrm{a}}$ & $1 \pm 0.018^{a}$ \\
\hline
\end{tabular}

There was a significant decrease in feed intake by hydrazine given animals (G3) and the reason could be its action on appetite, thus there was a drastic change in excreta quantity of the animals exposed to hydrazine, most mutagens are found to reduce apetite (Proctor and Hughes, 1978). This is in correlation with feed intake by animals. $O$. willei treatment enhanced the quantity of excreta in hydrazine exposed animals (G3) (Table 1), because most cyanobacteria are known as dietary supplements. There was an increase in the gravimetry of various internal organs like liver, lungs, spleen and kidney due to hydrazine exposure. Hydrazine was found to cause a dose related increase in liver weight and a decrease in hepatic glutathione (Timbrell et al., 1982). There was a reduction in the gravimetry of immune system in 0 . willei treated group (G4), thus it proved to possess bioactivity (Table 1).

Reduction in bleeding time and clotting time was noticed in hydrazine exposed animals (G3) (Table 2). There was an improvement in the bleeding time of $O$. willei treated groups (G4) and also in the group left for recovery after $O$. willei treatment (G5). Samrot and Thirunalasundari (2010) found Oscillatoria willei to improve bleeding time and clotting time in cigarette smoke exposed mouse. WBC count was enhanced to around $40 \%$ in hydrazine exposed animals (G3). WBC count was found to be reduced in the treated groups. RBC count and hemoglobin content was reduced to certain extent due to hydrazine exposure (G3) (Table 2). This reduction in RBC count was enhanced by
O. willei (G4) treatment. Samrot and Thirunalasundari (2010) found $O$. willei to have activity on WBC, RBC and hemoglobin content of cigarette smoke exposed mouse.

Lymphocyte, monocytes, three different types of granulocytes, natural killer cells and null cells account for differential count. These cells play a major role in the defense mechanism of the host either in a specific or non specific way. Monocyte count was enhanced to the tune 2.5 to 3 times in hydrazine exposed animals. Lymphocyte count was found to be reduced in hydrazine given animals (Table 2). Young (1995) suggested that hydrazine may decrease blood lymphocyte concentrations. Basophils and eosinophils count were also found to be increased. Neutrophils count was found to be reduced (Table 2). Lymphocytes count was also reduced which in turn indicates the status of specific immune response. There was an increase in lymphocyte count in $O$. willei treated group (G4). This could be probably due to the effect of $O$. willei in $\mathrm{CMI}$ or humoral response. O. willei treatment (G4) reduced basophil count which in turn indicates a reduction in the inflammation process.

Interleukin-2 (IL-2) is a cytokine that is a critical promoter of a cell mediated immune response by activating and promoting the differentiation of T-lymphocytes. Production of IL-2 was enhanced by hydrazine exposure (Figure 1). It is suggested that hydrazine has the potential to modify immune function through interference with IL-2 production and especially the lymphoproliferative response to IL- 


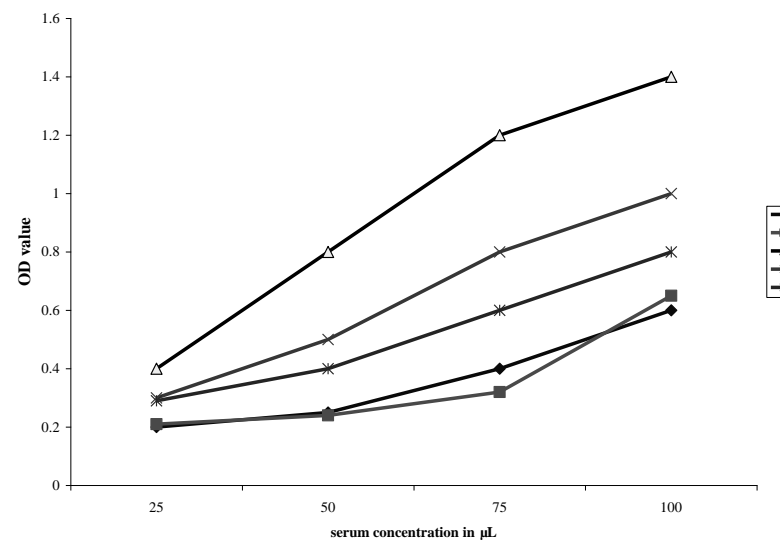

Figure 1: IL-2 activity of control vs test (hydrazine injected and followed by treatment)

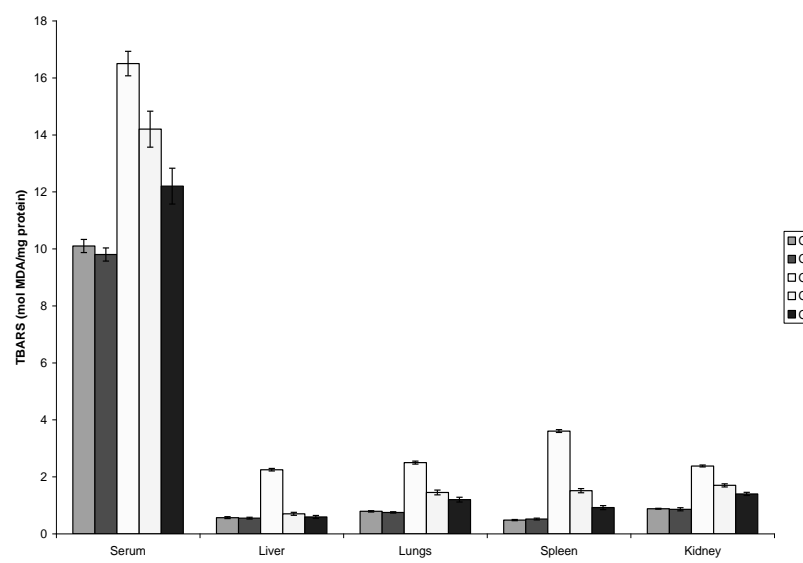

Figure 2: Serum and tissue TBARS Control vs Tests (Hydrazine injected and followed by treatment

2.TBARS (thiobarbituric acid reactive substance), an index of lipid peroxidation and oxidative stress was elevated in G3. The elevation was more than $50 \%$ and 5 fold increase in serum TBARS and tissue TBARS respectively in $\mathrm{G} 3(\mathrm{p}<0.0001)$. Again its level has come down to an appreciable and significant level due to $O$. willei treatment $(\mathrm{G} 4)(\mathrm{p}<0.05)$ (Figure 2).

Hydrazine exposure (G3) enhanced the reducing sugar, total protein, albumin, cholesterol, triglyceride, LDL and VLDL content of the test group animals $(p<0.001)$ than the control (G1 and G2). All the ill effects have been more reduced and found to nearing to normal in $O$. willei treated animals allowed for recovery study (G5) (Table 3). Samrot and Thirunalasundari (2010) also found $O$. willei to reduce the ill effects caused by cigarette smoke. Liver function tests are represented by enzymes like SGOT, SGPT, alkaline phosphatase, acid phosphatase, GGT and bilirubin. When assessed it was found that all the liver function enzyme and bilirubin were elevated in G3 $(p<0.001)$ (Table 4). Though there was no change in SGOT level among the $O$. willei treated groups (G4) than hydrazine exposed animals (G3), there was an appreciable and significant change in other parameters like SGPT, alkaline phosphatase, acid phosphatase, GGT and bilirubin $(p<0.001)$ (Table 5). O. willei was found to reduce these enzymes activity in cigarette smoke exposed mice (Samrot and Thirunalasundari, 2010).
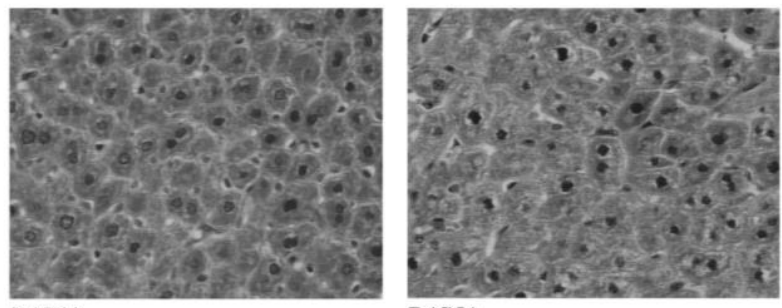

A (G1)

$B(G 2)$
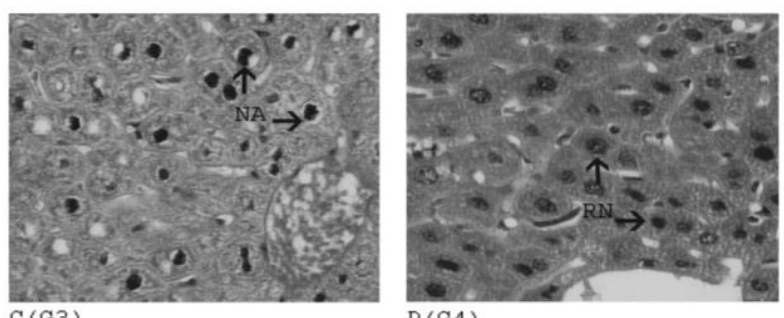

C (G3)

$\mathrm{D}(\mathrm{G} 4)$

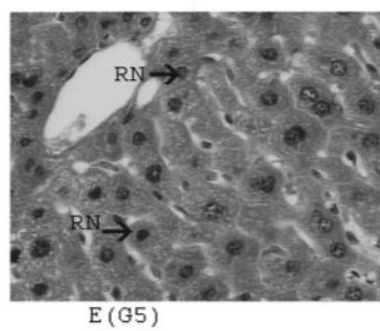

Figure 3 Photography showing the effect of hydrazine on lung tissue (40X magnification)

NA- Nuclear abnormality

$\mathrm{RN}$ - Recovering nuclei

G1 - control, G2 - Positive control, G3 -Test (injected with hydrazine) showing cytolysis and nuclear abnormality, G4 - Test (injected with hydrazine and treated with $O$. willei extract) showing reduction in nuclear abnormality, G5 - Test (injected with hydrazine, treated with $O$. willei extract and left for recovery study), showing more nuclei to recover from abnormality.

Kidney function test represented by uric acid and urea found to be enhanced to several fold $(p<0.001)$, due to hydrazine exposure (G3). Uric acid level was brought back to normal and comparable to control by $O$. willei treatment (G4) (Table 4). Even O. willei was found to have action against the elevated level of uric acid, urea and creatinine in cigarette smoke exposed mice (Samrot and Thirunalasundari, 2010).

Nuclear abnormality and cytolysis of the hepatocytes were observed in the hydrazine given animals (Figure 4). This might have been caused by oxidative damage induced 
and hydrazine. A dose of $20 \mathrm{mg} / \mathrm{kg}$ of hydrazine caused accumulation of lipid, swelling of mitochondria and the appearance of microbodies in periportal and midzonal hepatocytes (Scales and Timbrell, 1982). O. willei treatment reduced the percentage of nuclear abnormality in hydrazine. The bioactive compounds present in $O$. willei might be the recovery of these abnormalities induced by hydrazine. Samrot and Thirunalasundari (2010) also found $O$. willei to reduce nuclear abnormalities induced by cigarette smoke in mice.
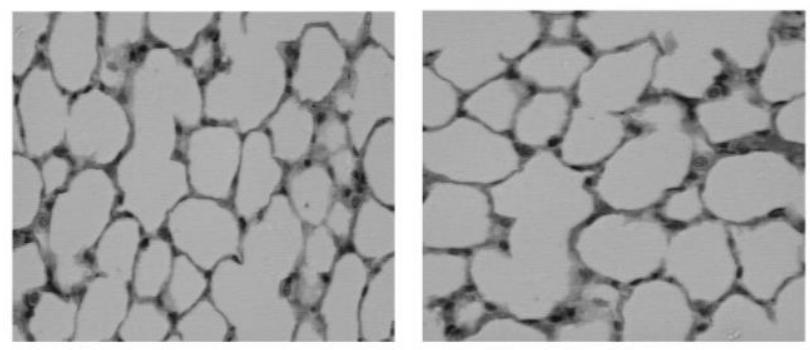

A (G1)

$\mathrm{B}(\mathrm{G} 2)$
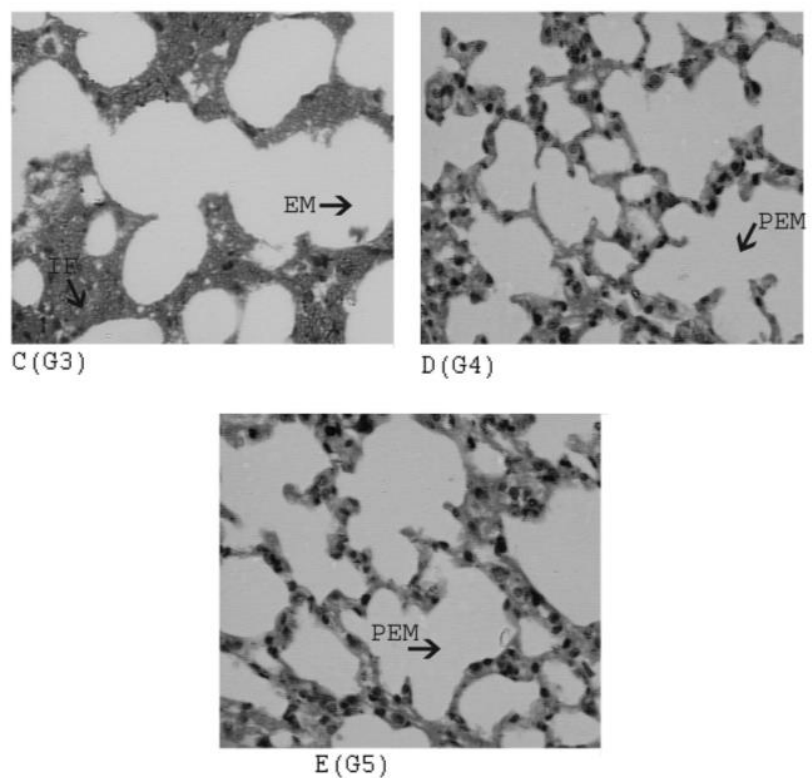

Figure 4 Photography showing the effect of hydrazine on lung tissue (40X magnification)

EM - Emphysema

PEM - Persistent Emphysema

G1 - control, G2 - Positive control, G3 -Test (injected with hydrazine) showing enlargement of airspace (Emphysema) and increased inflammation, G4 - Test (injected with hydrazine and treated with $O$. willei extract) showing reduction in inflammation, G5 - Test (injected with hydrazine, treated with $O$. willei extract and left for recovery study), showing reduction in inflammation.

Inflammation and airspace enlargement i.e. permanent emphysema was induced by hydrazine exposure in mice (Figure 4). Cigarette smoke also found to create permanent emphysema. Hydrazine vapor is a potent ocular and upper respiratory tract irritant in humans and common laboratory animals and is absorbed readily through intact skin, the lungs, and the gastrointestinal tract (Reinhart et al., 1981). Latendresse et al (1995) also suggested that hydrazine-induced local inflammation likely played a minimal role, if any, in the promotion and progression of the tumors. $O$. willei treatment played a major role in reducing the inflammation induced by hydrazine. This again proves the bioactive potency of $O$. willei.

Qualitative analysis of $\mathrm{O}$. willei extract for secondary metabolites revealed the presence of tannins, saponins, flavanoids and terpenoids. Ethanolic extract of $O$. willei when analysed by GC-MS found to have fourteen major components. The retention time varied from 3.02 in Butane 1,1-diethoxy- to 39.56 in Olean-12-ene. Peak area percentage varied from $0.04 \%$ in 1,2,3,4,5Cyclopentanepentol to $3.87 \%$ Olean-12-ene. Cyanobacteria are well known to produce various types of bioactive compounds that include antiviral, antibacterial, antifungal, immunomodulatory, antitumor and anticancer compounds (Samrot and Thirunalasundari, 2010; Nogle and Gerwick, 2002; Teicher et al., 2000; Jaki et al., 2000)

\section{CONCLUSION}

O. willei, a photosynthetic prokaryote known to possess secondary metabolites with pharmacological activities could be a remedy for hydrazine induced toxicity in animals. If further explored and confirmed one or more compounds of $O$. willei origin could be of use to human beings as cure for hydrazine/chemical induced pathological changes.

\section{REFERENCES}

Chamorro, G., Salazar, S., Castillo, L., Steele, C. and Salazar, M. (1997). Reproductive and peri - and postnatal evaluation of Spirulina platensis in mice. Journal of Applied Phycology 9: 107-112.

Edeoga, H.O., Okwu, D.E. and Mbaebie, B.O. (2005). Phytochemical constituents of some Nigerian medicinal plants. African Journal of Biotechnology. 4 (7): 685-688.

Falch, B.S., Konig, G.M., Wright, A.D., Sticher, O., Angerhofer, C.K., Pezzuto, J.M. and Bachmann, H. (1995). Biological activities of cyanobacteria: evaluation of extracts and pure compounds. Planta Medica. 61(4): 321-328.

Hoffmann, D. and Hecht, S.S. (1990). Advances in tobacco carcinogenesis. In: Handbook of Experimental Pharmacology, C.S. Cooper, and P.L Grover, eds. Heidelberg, Germany: Springer-Verlag. 94(I): pp. 63-102.

Hudson, L. and Hay, F.C. (1989). The Lymphocyte: its role and function. Practical immunology. Third edition. Blackwell Scientific Publications Oxford, England. 3: pp. 86-94

Humason, G.L. (1979). Animal tissue techniques. WH 
Freeman \& Co. San Francisco.

International Agency for Research on Cancer. (1999). Re-Evaluation of Some Organic Chemicals, Hydrazine and Hydrogen Peroxide (Part III). IARC Monographs on the Evaluation of Carcinogenic Risks to Humans, Lyon. World Health Organization. $\mathbf{7 1 .}$

Jaki, B., Heilmann, J. and Sticher, O. (2000). New antibacterial metabolites from cyanobacteria Nostoc commune (EAWAG 122b). Journal Natural Products 63(9):1283-1285.

Latendresse, J.R., Marit, G.B., Vernot, E.H., Haun, C.C. and Fleming, C.D. (1995). Oncogenic potential of hydrazine in the nose of rats and hamsters after 1 or 10 1-hour exposures. Fundamental and Applied Toxicology 27(1):33-48.

Liu, Y.Y., Schmeltz, I. and Hoffmann, D. (1974). Chemical studies on tobacco smoke. Quantitative analysis of hydrazine in tobacco and cigarette smoke. Analytical Chemistry 46(7):885-889.

National Research Council. Hydrazine. (1996). In: Spacecraft Maximum Allowable Concentrations for Selected Airborne Contaminants, Washington, DC: National Academy Press. 2: pp. 213-233.

Nogle, L.M. and Gerwick, W.H. (2002). Isolation of four new cyclic depsipeptides, antanapeptins $A-D$ and dolastatin 16 from a Madagascan collection of Lyngbya majuscula. Journal Natural Products 65(1): 21-24.

Ochoa, M., Wittes, R.E. and Krakoff, I.H. (1975). Trial of hydrazine sulfate (NSC-150014) in patients with cancer. Cancer Chemotherapy Reports 59(6):11511154.

Proctor, N.H., and Hughes, J.P. (1978). Chemical hazards of the working place. J.P.Lippincott Company: Philadelphia. pp.284-285.

Reinhart, K.L., Shaw, P.D., Shield, L.G., Gloer, J.B., Harbour, G.C. and Koker, M.E.S. (1981). Marine natural products as sources of antiviral, antimicrobial and antineoplastic agents, Pure and Applied Chemistry 53:795.

Samrot, A.V. and Thirunalasundari, T. (2010). Therapeutic effect of Oscillatoria willei - A marine cyanobacterium in mice exposed to cigarette smoke. Journal of Pharmacy Research 3(9): 2286-2290.

Sarulatha, S. (2001). Immunomodulatory Compound from Marine Oscillatoria willei BDU 130511, M.Sc. Thesis, Microbiology Department, Bharathidasan University, Tiruchirappalli - 620024.

Scales, M.D. and Timbrell, J.A. (1982). Studies on hydrazine hepatotoxicity. Pathological findings. Journal of Toxicology and Environmental Health 10:941-953.

SchiessI, H.W. (1995). Hydrazine and its Derivatives. In: Kirk-Othmer Encyclopedia of Chemical Technology, Ed., J.I. Kroschwitz, and M. Howe-Grant, New York: John Wiley and Sons. 13 (4): 560-606.

Sood, R. (2004). Clinical Hematology. Medical laboratory technology - Methods and interpretations Jaypee Brothers Medical Publishers (P) Ltd. New Delhi.

Teicher, B.A., Forler. P., Menon, K,. Phares, V.,
Amsrud, T. and Shih, C. (2000). Cryptophycin 52 and Cryptophycin 55 in sequential and simultaneous combination treatment regimens in human tumor xenografts. In Vivo. 14(4):471-480.

Timbrell, J.A., Scales, M.D., and Streeter, A.J. (1982). Studies on hydrazine hepatotoxicity. 2.biochemical findings. Journal of Toxicology and Environmental Health.10:955-968.

U.S. Environmental Protection Agency. (1991). Hydrazine/Hydrazine Sulfate (CASRN 302-01-2). Integrated Risk Information System, U.S. Environmental Protection Agency.

Young. (1995). Effects of Drugs on Clinical Laboratory Tests 4th ed. AACC Press.

Zhu Q.F. (1991). Short term assay of colon carcinogeninduction of micronuclei and apoptosis by dimethylhydrazine in the mouse colon crypt cells. Zhongua Zhong Liu Za Zhi. 13(3):171-173. 